\title{
Family based association analysis of the IL2 and IL15 genes in allergic disorders
}

\author{
Ulla Christensen ${ }^{1}$, Annette Haagerup ${ }^{1,2}$, Helle G Binderup ${ }^{1}$, Jørgen Vestbo ${ }^{3,4}$, \\ Torben A Kruse ${ }^{5}$ and Anders D Børglum ${ }^{*, 1}$
}

${ }^{1}$ Institute of Human Genetics, The Bartholin Building, University of Aarhus, Aarhus C, Denmark; ${ }^{2}$ Department of
Paediatrics, Aarhus University Hospital, Skejby, Denmark; ${ }^{3}$ Institute of Preventive Medicine, Kommunehospitalet,
Copenhagen, Denmark; ${ }^{4}$ North West Lung Centre, Wythenshawe Hospital, Manchester, UK; ${ }^{5}$ Department of Clinical
Biochemistry and Genetics, Odense University Hospital, University of Southern Denmark, Odense, Denmark

Allergic diseases affect an increasing number of individuals and are a major global health problem. A substantial genetic contribution in the aetiology of allergic diseases is well documented. We have previously reported linkage of allergic diseases and atopy to the region harbouring the IL2 gene (4q27). IL 15 is located approximately $20 \mathrm{Mb}$ distal to IL2. The two genes encode cytokines that are structurally and functionally related, both inducing T-cell activation and proliferation. We screened the two genes for sequence variation and applied the seven single-nucleotide polymorphisms (SNPs) identified in a family based association study of two Danish samples comprising a total of 235 families with allergic diseases. None of the IL15 SNPs showed significant association and the haplotype analysis yielded inconsistent results in the two samples. In contrast, the two IL2 SNPs showed association both separately and in haplotypes with several atopic phenotypes, most significantly with IgE-mediated allergy. (single SNP $P$-value $\mathbf{0 . 0 0 0 5}$ for positive skin prick test, haplotype $P$-value $\mathbf{0 . 0 1 9}$ for positive RAST test). To our knowledge, this is the first study reporting association between IL2 and IgE-mediated allergy, asthma and atopic eczema. The SNP (rs2069762) that showed the most consistent results is located in the promoter and has previously been shown to influence the level of IL2 expression. We suggest that the observed overtransmission of the T allele of this SNP may convey increased susceptibility to allergic disease by skewing the Th1/Th2 balance towards Th2.

European Journal of Human Genetics (2006) 14, 227-235. doi:10.1038/sj.ejhg.5201541; published online 7 December 2005

Keywords: allergic disease; SNP; association analysis; promoter; Th1/Th2 balance

\section{Introduction}

Allergic disease is affecting an increasing number of individuals. Worldwide, asthma affects 155 million people. Even a larger number of individuals suffer from allergic rhinitis (hay fever). ${ }^{1}$ Atopic dermatitis (AD) at present

\footnotetext{
*Correspondence: Professor AD B $ø$ rglum, Institute of Human Genetics, The Bartholin Building, University of Aarhus, DK-8000 Aarhus C, Denmark. Tel: +458942 1672; Fax: +4586123173 ;

E-mail: anders@humgen.au.dk

Received 14 April 2005; revised 10 August 2005; accepted 21 October 2005; published online 7 December 2005
}

affects $21 \%$ of Danish children. ${ }^{2}$ Due to the high incidence, the personal morbidity and the social costs, the allergic diseases are a major global health problem.

The pathogenesis of these disorders is multifactorial and poly- or oligogenic. Family, twin, and adoption studies have demonstrated the genetic component of the aetiology to be considerable. ${ }^{3-8}$ Twin studies of asthma and rhinitis have estimated the heritability to $60-73 \%$. For $\mathrm{AD}$, 0concordance rates in monozygotic twins are reported to be 0.86 , compared to 0.21 in dizygotic twins. ${ }^{9}$

Several genome scans have pointed out candidate regions for allergic disease. We have previously reported 
linkage of allergic rhinitis to chromosome 4q24-27 in a genome scan of Danish sib-pair families (LOD score 3.26). ${ }^{10}$ In a recent fine-mapping study, we found evidence of linkage of additional atopy phenotypes to the same region, including increased serum levels of specific IgE (positive RAST test) and asthma. ${ }^{11}$

The IL2 gene is located at $4 \mathrm{q} 27$ and consists of four exons. IL2 is important for the proliferation of activated $\mathrm{T}$ lymphocytes and thereby for the activation of the phagocytes to destroy uptaken material (Th1activation) and for the B-lymphocytes to produce antibodies (Th2-activation). Other important functions are the central role of IL2 in enhancing AICD (activation-induced cell death) of $\mathrm{T}$ lymphocytes, and thereby the elimination of self-reactive cells, ${ }^{12}$ and the termination of lymphocyte response by inducing the production of suppressive $\mathrm{T}$ cells. ${ }^{13}$ Due to this central position in the regulation of the immune response, IL2 is an obvious candidate gene for allergic disease.

The IL15 gene is located at 4q31. IL15 is functionally and structurally related to IL2. They share the receptor subunits IL2R $\beta$ and $\gamma_{c}$ and both cytokines induce T cell activation and proliferation. The number of CD $8+$ memory T cells is decreased by IL 2 and increased by IL15; thus, the number of these cells in animals is controlled by the balance between IL15 and IL2. ${ }^{14}$ This balance also controls selftolerance, as the IL2-induced AICD is inhibited by IL15. There are essential differences between the cells producing the cytokines: whereas IL2 is produced only by activated Th1 cells, IL15 is transcribed in a variety of cell types including epithelial cells and monocytes, but not primary T cells. ${ }^{15}$

In order to examine the involvement of IL2 and IL15 in allergic disease, we screened a number of individuals for variations in the genes. Subsequently, we performed an association analysis of the identified single-nucleotide polymorphisms (SNPs) in two Danish family samples including 235 families with a minimum of two sibs suffering from atopic disease.

\section{Materials and methods Subjects}

Two Danish family samples were studied: samples A and B (Table 1). In sample A, 135 nuclear families with asthmatic sib pairs were enrolled primarily from patient's records in four clinical centres in Eastern, Western and Central part of Denmark. Inclusion criteria were recurrent cough, wheezing and dyspnoea, and a positive methacholine challenge using the methods described by Yan et al. ${ }^{16}$ Both affected siblings were aged 15-45 years. A questionnaire was filled in for every family member. Skin-prick tests using 10 common aeroallergens and lung function measurements including FEV1 and FVC were performed on all subjects. Blood samples were analysed for allergen-specific IgE (CAP phadiatop; Pharmacia Upjohn, Copenhagen, Denmark); positive test was defined as $\operatorname{IgE} \geq 0.35 \mathrm{kU} / \mathrm{l}$ for one or more of the allergens. The rhinitis and AD (eczema) phenotypes were self-reported in the questionnaires. Details about sample A have been described previously. ${ }^{17}$

Sample B included a total of 424 individuals from 100 Danish atopic families enrolled in the ITA project. Recruitment, examination and clinical information are described previously. ${ }^{10,11}$ In short, patients were recruited through four paediatric and one adult outpatient allergy clinic in Western Denmark. Inclusion criteria were a minimum of two atopic siblings with doctor diagnosed asthma, hay fever or AD and reported effect of appropriate medication. Mean age among the offspring was 10.8 years. As in sample A, male/female ratio was equal to random distribution. All subjects were clinically examined and questionnaire tested by the same doctor. Atopic disease was diagnosed by this doctor according to standard criteria in consensus with a second doctor evaluating the questionnaires only. Blood was drawn for DNA extraction and serum measurement of specific IgE to 11 common allergens (CAP RAST FEIA, Pharmacia Upjohn); positive test defined as above.

\section{Sequencing and genotyping}

Genomic DNA was isolated from blood samples according to standard procedures. The IL2 and IL15 genes were

Table 1 Structure of the two family samples analysed

\begin{tabular}{|c|c|c|c|c|}
\hline & \multicolumn{4}{|c|}{ Number of families with affected children } \\
\hline & Asthma & Rhinitis & Atopic dermatitis & Positive RAST test \\
\hline \multicolumn{5}{|l|}{ Sample $A$ (135 families) } \\
\hline Families with one affected child & 0 & 47 & 51 & 35 \\
\hline Families with two affected children & 135 & 74 & 68 & 73 \\
\hline Total & 135 & 121 & 119 & 108 \\
\hline \multicolumn{5}{|l|}{ Sample B (100 families) } \\
\hline Families with one affected child & 31 & 36 & 33 & 36 \\
\hline Families with two affected children & 45 & 35 & 34 & 40 \\
\hline Families with three affected children & 12 & 8 & 6 & 7 \\
\hline Total & 88 & 79 & 73 & 83 \\
\hline
\end{tabular}


screened for sequence variation in the coding sequences, intron/exon boundaries, and $1405 \mathrm{bp}$ (IL2) and $485 \mathrm{bp}$ (IL15) of the promoter regions by direct sequencing using Big Dye Terminator Cycle Sequencing Kit (Applied Biosystems). After ethanol precipitation, the resolved products were analysed on an ABI-310 sequenator from Applied Biosystems. Both strands were analysed.

Genotyping was performed by multiplex single base extension (SBE) technology using the SNaP-shot Kit, according to the manufacturer's recommendations (Applied Biosystems). Standard PCR conditions were used for both sequencing and genotyping. Primer sequences are shown in Table 2. Two investigators performed scoring of the genotypes independently; in cases of disagreement the results were reviewed and re-analysed. Genotypes were tested for Hardy-Weinberg equilibrium and Mendelian inheritance. Furthermore, around 150 genotypes were analysed twice: 70 genotypes analysed by both direct sequencing and SBE, and around 80 genotypes analysed twice by SBE. No inconsistencies were identified, indicating a genotyping error rate of less than $0.67 \%$.

\section{Statistical analysis}

Pairwise linkage disequilibrium (LD) was calculated using Simwalk $2^{18}$ and the GOLD software package (http:// www.sph.umich.edu/csg/abecasis/GOLD). ${ }^{19}$

The family based association analysis used the FBAT test allowing for analysis of single SNPs and haplotypes

Table 2 Primers used for PCR amplification, sequencing and genotyping

\begin{tabular}{|c|c|c|c|c|}
\hline Gene & Region & Type & $\begin{array}{c}\text { Position UCSC } \\
\text { May } 04 \text { assembly }\end{array}$ & Sequence \\
\hline IL2 & $\begin{array}{l}\text { Promoter } \\
\text { Promoter } \\
\text { Promoter } \\
\text { Promoter } \\
\text { Promoter } \\
\text { Promoter } \\
\text { Promoter } \\
\text { Promoter } \\
\text { Promoter } \\
\text { Exon } 1+2 \\
\text { Exon } 1+2 \\
\text { Exon 1b } \\
\text { Exon } 1 \mathrm{a} \\
\text { Exon } 3 \\
\text { Exon } 3 \\
\text { Exon } 4 \\
\text { Exon } 4\end{array}$ & $\begin{array}{l}F \\
R \\
F \\
R \\
F \\
R \\
\text { SNP } \\
F \\
\text { R } \\
\text { F } \\
\text { R } \\
\text { SNP } \\
\text { SNP } \\
\text { F } \\
\text { R } \\
\text { F } \\
\text { R }\end{array}$ & $\begin{array}{r}123735586 \\
\\
123735076 \\
123735089\end{array}$ & $\begin{array}{l}\text { AGTGGTTTTTGGAGTCAGTA } \\
\text { TATACTTCTAATTTAACCTGG } \\
\text { CTITACAAGGACTCTCTTTGA } \\
\text { GAGGTACTGTTTAACGCTATT } \\
\text { TGTACATAGACATTAAGAGAC } \\
\text { AGCCCACACTTAGGTGATAGC } \\
\text { CACATGTTCAGTGTAGTITTA } \\
\text { CTITTGTATCCCCACCCCCT } \\
\text { TGCAAGACTTAGTGCAATGC } \\
\text { GTTCCCTATCACTCTTTAAT } \\
\text { TTTCATATTACTTTGAATTTATT } \\
\text { AAAATCATCTGTAAATCCAG } \\
\text { GCTACAACTGGAGCATTTAC } \\
\text { ATTAATTCTGATTCTCACCTC } \\
\text { TGGTACTTTCCCCCTACTT } \\
\text { TATAAGGTAAACTACTCTCTA } \\
\text { TACATTCAACATAAATATAAAAT }\end{array}$ \\
\hline IL15 & $\begin{array}{l}\text { Promoter } \\
\text { Promoter } \\
\text { Promoter } \\
\text { UTR } \\
\text { UTR } \\
\text { UTR } \\
\text { UTR } \\
\text { UTR } \\
\text { UTR } \\
\text { Exon 3 } \\
\text { Exon 3 } \\
\text { UTR } \\
\text { UTR } \\
\text { Exon 4 } \\
\text { Exon 4 } \\
\text { Exon 5 } \\
\text { Exon 5 } \\
\text { Exon 6 } \\
\text { Exon 6 } \\
\text { Exon 7 } \\
\text { Exon 7 } \\
\text { Exon 8 } \\
\text { Exon 8 }\end{array}$ & $\begin{array}{l}\text { F } \\
R \\
\text { SNP } \\
F \\
R \\
\text { SNP } \\
F \\
R \\
\text { SNP } \\
\text { F } \\
\text { R } \\
\text { SNP } \\
\text { SNP } \\
\text { F } \\
\text { R } \\
F \\
\text { R } \\
\text { F } \\
\text { R } \\
F \\
R \\
F \\
R\end{array}$ & $\begin{array}{l}142914864 \\
142928055 \\
142932872 \\
142998069 \\
142998123\end{array}$ & $\begin{array}{l}\text { ATGGCATGCAAATCACTCAGC } \\
\text { CACCAGCCACCGGTCTCCT } \\
\text { AACATTTCCCCTAGTTGGAC } \\
\text { TTAGGTGTCTTCATTCTTAAC } \\
\text { ACACTTCCTGGTGCTTCAG } \\
\text { TTTCACCCATAGTCCCAAGTAC } \\
\text { TCACATTTCTCAAGGAATGG } \\
\text { GGAATCTGGCCTGCTTCC } \\
\text { ACTTCCATCAGGTGTTGTTC } \\
\text { TTAAAAGGTAGGTGTTCAATAAG } \\
\text { ACTCTGAGATTCAGAGGACC } \\
\text { CACTAGTAAGAAAAAGAAAG } \\
\text { GATTGTATTGTAGGAGGCAT } \\
\text { TTTAGACCTAGAAATATGTTGAC } \\
\text { TCCAAGGACAATCATCATGAC } \\
\text { CTCTTTTGCTTATAGTATTCATC } \\
\text { TGGTTTCCTTAAGACAGACAG } \\
\text { ATGTTTCAGTAGGTTGTTCTC } \\
\text { ACCATATATTATAGAAACACACC } \\
\text { GTAAAATTTCTTAAGGATATTGTG } \\
\text { AATGACTTCTCCAAATCAGGC } \\
\text { ATGGTTCAAACGATATGATATTC } \\
\text { TATGTCTAAGCAGCAGAGTGA }\end{array}$ \\
\hline
\end{tabular}

${ }^{\mathrm{a}} \mathrm{F}$ : forward, R: reverse, SNP: primer immediately adjacent to the SNP used in the SNaP-shot reaction (Applied Biosystems) (see Materials and methods).

bURL: http://genome.ucsc.edu. 
(HBAT). ${ }^{20,21}$ Primarily, the data were analysed using an additive model, which does not assume any specific mode of inheritance and is in general the most sensitive test. ${ }^{21}$ The additive model is equivalent to the classic transmission disequilibrium test (TDT). ${ }^{22}$ In addition, we also analysed the data assuming dominant and recessive modes of inheritance. The basic null-hypothesis tested by the FBAT program is 'no linkage and no association', and the first $P$-values (before the slashes) in Table 5 and 6 relate to this null-hypothesis. However, in the presence of linkage and when there is more than one affected child per pedigree, which is the case in most of our data, the FBAT program offers the possibility of testing the nullhypothesis 'linkage but no association' by use of the empirical variance for the test statistic. The second $P$-values (after the slashes) in Table 5 and 6 are calculated using the empirical variance, thus testing for association in the presence of linkage.

$P$-values $<0.05$ are referred to as significant. For each gene, none of the tests performed both regarding phenotypes, models and SNPs/haplotypes are independent, and no correction for multiple testing was performed.

\section{In silico analysis}

The impact of an SNP on potential binding sites for transcription factors was assessed using the program Matinspector (URL) (www.genomatix.de). ${ }^{23,24}$ This program utilizes a library of matrix descriptions for transcription factor binding sites to locate matches in sequences and assigns a quality rating of matches. Thus, the influence of an SNP on the binding of possibly important transcription factors can be investigated by loading the program with the wild type and the variant sequence, respectively. The possible effect of an SNP on splicing was investigated using the programs ESEfinder release 2.0 (http://rulai.cshl.edu/ tools/ESE) ${ }^{25}$ and NNSPLICE version 0.9 (www.fruitfly.org/ seq_tools) ${ }^{26}$ and comparing the results from analyses of the allelic sequences. ESEfinder identifies putative exon splicing enhancers responsive to the human SR proteins SF2/ASF,
SC35, SRp40 and SRp55, and NNSPLICE predicts potential splice sites based on neural network. Both programs assign quality ratings for the predictions.

\section{Results}

In order to identify potentially functional sequence variations in the IL2 and IL15 genes, we analysed 10 unrelated atopic patients from families that showed evidence of linkage to the region (4q27) in a recent linkage study (sib-pairs sharing both haplotypes identical by descent) ${ }^{11}$ and two healthy controls. Two SNPs were identified in IL2 and five in IL15 (Table 3).

These seven SNPs were subsequently applied in a family based association analysis of two Danish samples comprising 135 and 100 atopic families, respectively. In addition, an apparently nonsynonymous SNP (rs3087209, Table 3) from dbSNP (http://www.ncbi.nlm.nih.gov/projects/SNP) was also tested in the two samples. However, this putative SNP showed no variation in the entire data set and is most likely not a true SNP, at least not in the Danish population.

The two IL2 SNPs, rs2069762 and rs2069763, were found to be in weak LD with each other with Lewontin's standardized disequilibrium coefficient $D^{\prime}=0.334 \quad(P<0.0001)$. The five IL5 SNPs showed a moderate degree of pair wise LD as shown in Table 4.

All variants were found to be in Hardy-Weinberg equilibrium

Table 4 Pairwise linkage disequilibrium of IL15 SNPS measured as Lewontin's standardized disequilibrium coefficient $D^{\prime a}$

\begin{tabular}{lcccc}
\hline & Rs1519551 & Rs2322262 & Rs1493012 & Rs2254514 \\
\hline Rs3806798 & 0.777 & 0.781 & 0.701 & 0.793 \\
Rs1519551 & & 0.584 & 0.601 & 0.513 \\
Rs2322262 & & & 0.889 & 0.901 \\
Rs1493012 & & & & 0.889 \\
\hline
\end{tabular}

${ }^{\text {aAll }} D^{\prime}$ values were statistically significant with $P$-values less than 0.001 .

Table 3 Single-nucleotide polymorphisms (SNPs) applied in the family based association study

\begin{tabular}{|c|c|c|c|c|c|}
\hline Gene & SNP & Rs number & $\begin{array}{c}\text { Position UCSC } \\
\text { May } 04 \text { assembly }\end{array}$ & Position in gene $e^{\mathrm{b}}$ & $\begin{array}{l}\text { Alleles (frequencies } \\
\text { in parentheses) }\end{array}$ \\
\hline IL2 & $\begin{array}{l}\text { SNP1 } \\
\text { SNP2 } \\
\text { SNP3 }\end{array}$ & $\begin{array}{l}\text { Rs2069762 } \\
\text { Rs2069763 } \\
\text { Rs3087209 }\end{array}$ & $\begin{array}{l}123735586 \\
123735076 \\
123735089\end{array}$ & $\begin{array}{l}\text { Promoter } \\
\text { Exon } 1 \text {, synonymous } \\
\text { Exon } 1 \text { nonsynonymous }\end{array}$ & $\begin{array}{l}\mathrm{T}(0.717), \mathrm{G}(0.283) \\
\mathrm{G}(0.622), \mathrm{T}(0.372) \\
\mathrm{T}(1.000), \mathrm{G}(0.000)\end{array}$ \\
\hline IL15 & $\begin{array}{l}\text { SNP1 } \\
\text { SNP2 } \\
\text { SNP3 } \\
\text { SNP4 } \\
\text { SNP5 }\end{array}$ & $\begin{array}{l}\text { Rs3806798 } \\
\text { Rs1519551 } \\
\text { Rs2322262 } \\
\text { Rs1493012 } \\
\text { Rs2254514 }\end{array}$ & $\begin{array}{l}142914864 \\
142928055 \\
142932872 \\
142998069 \\
142998123\end{array}$ & $\begin{array}{l}\text { Promoter } \\
\text { Intron } 1 \\
\text { Intron } 1 \\
\text { Intron } 2 \\
\text { Exon 3, UTR }\end{array}$ & $\begin{array}{l}\mathrm{A}(0.902), \mathrm{T}(0.098) \\
\mathrm{A}(0.577), \mathrm{G}(0.423) \\
\mathrm{T}(0.736), \mathrm{C}(0.264) \\
\mathrm{A}(0.567), \mathrm{G}(0.433) \\
\mathrm{C}(0.720), \mathrm{T}(0.280)\end{array}$ \\
\hline
\end{tabular}

\footnotetext{
aURL: http://genome.ucsc.edu/

bUTR: untranslated region.

${ }^{c}$ Frequencies in two family samples combined. No significant difference in allele frequencies was observed between the two samples (results not shown).
} 


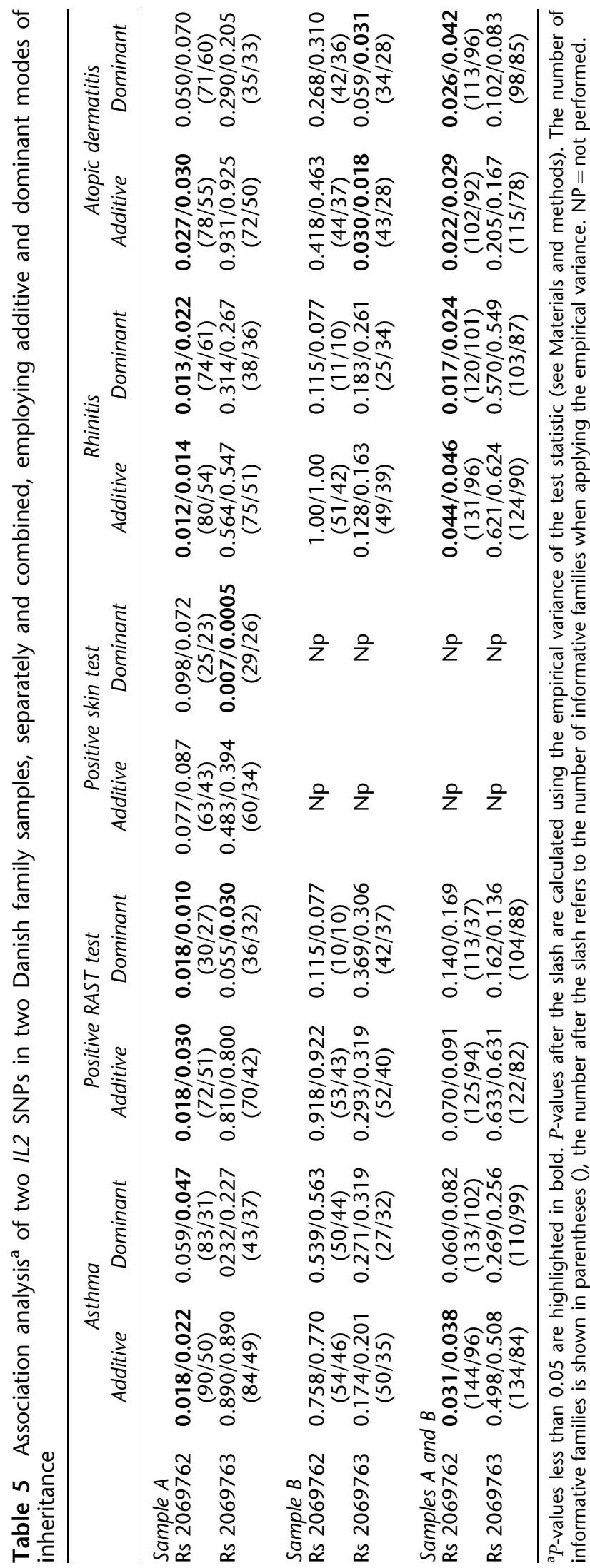

\section{IL2 association analysis}

Table 5 presents the results of the association analysis of the two IL2 SNPs analysed separately. The promoter variant (rs2069762) showed significant association with all three clinical phenotypes asthma, rhinitis, $\mathrm{AD}$, and positive RAST test in sample A (with $P$-values between 0.01 and 0.05 ). The $T$ allele was transmitted more frequent than what would be expected by chance; the $G$ allele less frequent. In sample $B$, this SNP did not show any significant association. However, analysis of the two samples combined showed again significant association with the three clinical phenotypes (whereas positive RAST test did not reach significance level with $P$-values around 0.1 ). For this promoter SNP, the additive and dominant models yielded similar $P$-values, while no evidence of association was observed under a recessive model. Likewise, no big differences were observed when the empirical variance was used to account for sibling genotype correlation for families with more than one child.

In silico analysis of this promoter variant using the program MatInspector revealed a potential binding site for heterodimers of TCF-11 (a transcription factor of the bzip type ${ }^{27,28}$ ) and MafG (a member of the Maf subfamily of the transcription factor $\mathrm{AP}-1^{29}$ ) when there was a $\mathrm{T}$ at the position of the polymorphism. Noteworthy, AP-1 is known to play a key role in the regulation of IL2 expression. ${ }^{30-32}$ Changing the $\mathrm{T}$ allele to a $\mathrm{G}$ eliminated this potential binding site reflecting a marked reduction in the predicted binding affinity of the complex.

The synonymous exon 1 SNP (rs2069763) showed highly significant association with the skin prick test under a dominant model ( $P$-value 0.0005 , using the empirical variance). The $\mathrm{T}$ allele was overtransmitted. This association could not be tested in sample B where the skin test was not performed. A significant association was also found with $\mathrm{AD}$, but only in sample $\mathrm{B}$ ( $P$-value 0.018 , additive model, empirical variance).

In silico analyses indicated that this variant might affect splicing of the transcript in two ways. First, according to the ESEfinder program, the score for potential binding sites for the splicing factors SC35, SRp40 and SRp55 was altered when changing the $G$ allele to T. A predicted binding site for SC35 was eliminated in the $\mathrm{T}$ allele sequence, a potential binding site for SRp55 existed only in the $\mathrm{T}$ allele sequence and the score for two potential SRp40 binding sites changed significantly when changing G to $\mathrm{T}$.

Second, splice site analyses using the NNSPLICE program found that the score for a potential splice site was 0.86 for the T-allele and only 0.57 for the G-allele. Thus the G-allele seems to inactivate a potential pseudo-splice site that might lead to a better splicing of the normal transcript.

The two SNPs in IL2 define the following four haplotypes mentioned with the promoter SNP first and estimated 
frequencies in parantheses H1: TT (0.378), H2: TG (0.342), H3: GG (0.269) and H4: GT (0.011). The results of the association analysis of these IL 2 haplotypes are presented in Table 6.

In sample A, evidence of under-transmission of the $\mathrm{H} 4$ haplotype was found in all phenotypes, most significantly for the asthma and rhinitis phenotypes and positive skinprick test ( $P$-values $0.004 / 0.03)$. In sample $B$, the same trend was observed for $\mathrm{H} 4$ without reaching significance (results not shown), but in the combined sample significant results were again observed, in particular for rhinitis and positive RAST test.

The H1 haplotype was found overtransmitted in sample $\mathrm{B}$ and in the combined sample for the AD phenotype with $P$-values around 0.02 . For both $\mathrm{H} 4$ and $\mathrm{H} 1$, the additive and dominant model yielded very similar results. For the $\mathrm{H} 4$ haplotype, the use of the empirical variance had quite a dramatic effect on the $P$-values, which were increased by a factor of around 3, suggesting that some of the positive signal in the default test were due to linkage and not to association alone. The same effect was not seen for the $\mathrm{H} 1$ results.

An overall test analysing the total distribution of all haplotypes and thereby introducing increased degrees of freedom was not significant in any of the phenotypes.

\section{IL15 association analysis}

None of the five SNPs in IL15 showed significant association with any of the atopic phenotypes when examined separately. The haplotype analysis examined haplotypes of varying length including two, three, four or all five SNPs in a sliding window fashion analysing neighbouring SNPs from one end of the gene to the other. The haplotypes mentioned below refer to the names (SNP 1-5) and order listed in Table 3 .

Few significant results were obtained. In sample A for the $\mathrm{AD}$ phenotype, evidence of under-transmission was observed for a set of frequent haplotypes with the same core (estimated frequencies around 0.4) under a recessive model. The haplotypes were TAT, TATA, and TATAC of SNP 1-3, 1-4 and 1-5, respectively. All haplotypes showed similar results, most significantly for the short TAT haplotype yielding a $P$-value of 0.025 that increased to 0.038 using the empirical variance.

In sample B, a set of haplotypes showed association with the two phenotypes postive RAST and rhinitis with positive RAST with equal results under both the dominant and additive model. The haplotypes were all under-transmitted, had a common core, and similar frequencies of around 0.05 , thus probably reflecting the same haplotype in all tests, namely: TACGT (SNP 1-5). Both 2-, 3-, 4-, and 5-point combinations of this haplotype yielded almost identical results, slightly more significantly for the ACGT haplotype showing a $P$-value of 0.005 , and 0.010 using the empirical variance. 
Neither of the haplotypes showing association in the two samples separately showed significant association in the combined sample. For positive RAST test, a single haplotype of SNP 2-4, ATG, with an estimated frequency of 0.033 was found under-transmitted with marginally significant $P$-values under both the additive and dominant model. The two models yielded identical $P$-values of 0.044 that were reduced to 0.036 using the empirical variance.

\section{Discussion}

We have examined the possible role of the IL2 and IL15 genes in the aetiology of atopy and allergic diseases in a family based association study of two Danish samples including a total of 235 families with allergic diseases. Both of the genes are obvious functional candidate genes, and IL2 is also a positional candidate gene as we have previously reported evidence of linkage to the region harbouring IL2 (4q27). ${ }^{10,11}$ The IL15 gene is located outside the maximal linkage signal approximately $20 \mathrm{Mb}$ distal to IL2.

We found association between IL2 and allergic diseases and IgE-mediated allergy (positive RAST test, positive skin prick test), both when testing the two IL2 SNPs separately and in haplotypes. This association was observed in particular in sample A, while significant replication in sample B was seen only for positive RAST test and AD and with different SNPs/haplotypes.

The paucity of significant results in sample B might partly be explained by demographic and clinical differences between the two populations. The two groups have different age distributions: All the individuals in sample A are older than 15 years whereas in sample B the probands are mainly children. Other inclusion criteria and diagnostics are not completely identical either. Thus, even though the diagnoses are the same, the underlying risk alleles might not be identical or of equal importance in the two groups.

For the IL2 promoter SNP (rs2069762), the G allele was transmitted less often than expected by chance to the atopic individuals, while the $\mathrm{T}$ allele conversely was transmitted more often than expected. Several observations indicate that this variant (often referred to as the '-330' polymorphism) has a functional impact on the expression of IL2. Hoffmann et al ${ }^{33}$ found that cultured peripheral blood lymphocytes from healthy individuals who were homozygous for the $\mathrm{G}$ allele produced over three times as much IL2 protein as individuals with T/T or G/T. In accordance with this observation, a recent study using a reporter-gene (luciferase) assay showed that the $G$ allele induced twice as high gene expression as the $\mathrm{T}$ allele in transfected Jurkat cells. ${ }^{34}$ However, the same study reported an apparently opposite effect in in vivo analyses, suggesting the existence of additional unknown polymorphisms affecting gene regulation.
Our in silico analysis of the promoter SNP revealed an impact on a potential binding site for the activation factor heterodimer of TCF-11 and the AP-1 protein MafG. Johnsen et $a l^{35}$ proposed that the TCF11/MafG complex may contribute to the negative regulation of transactivating transcription. This corroborates that the T allele may induce a relative decrease in $I L 2$ expression and offers a possible molecular explanation that should be experimentally tested.

Since IL2 is a Th1 cytokine, a variant that diminishes the IL2 production will tend to skew the Th1/Th2-balance towards Th2, which is typical for atopic individuals. Thus, the results showing decreased IL2 expression for the T allele as opposed to the $\mathrm{G}$ allele correlate well with our results. That is, the observed overtransmission of the $\mathrm{T}$ allele may convey an increased susceptibility to atopy and allergic disease by a relative decrease in IL2 expression.

Our results for the IL2 promoter SNP contradict the findings of a recent study, indicating that individuals homozygous for the $G$ allele may have an increased risk of rhinitis. ${ }^{36}$ However, in the present study, the haplotype results and the strong association observed between the synonymous exon 1 SNP (rs2069763) and positive skin prick test suggest that other IL2 variants might be of functional importance. Thus, in different populations different functional variants may predominate and, due to LD between the variants, possibly give rise to conflicting results.

The synonymous exon SNP disclosed exceedingly significant association with the skin prick test. Unfortunately, this association could not be tested in sample B where prick test was not performed. The fact that this SNP did not show significant single marker association using other models than the dominant model except for the AD phenotype in sample B, and only showed moderately significant association with positive RAST test (which normally correlates well with skin prick test) in sample A indicates, though, that this result should be interpreted with some caution.

However, haplotype analyses including this variant revealed significant results for all phenotypes in both sample A and the combined sample (except for asthma in the combined sample), and the results of the in silico analysis indicated a possible impact of the variant on splicing mechanisms. Functional analyses are needed to clarify the latter.

The two IL2 variants may actually influence the disease risk as indicated by the analyses mentioned above, but it should be kept in mind that the associations might also merely reflect LD to one or more causal variants in the surrounding region. Data provided by the HapMap project (www.hapmap.org) show extended LD in the region with a large, relatively well-defined haplotype block of around $580 \mathrm{~kb}$. Besides IL2 the block contains two genes: Testis nuclear RNA-binding protein (Tenr) and interleukin 21 (IL21). IL21 is a member of the family of immunomodulatory cytokines also including IL2 and IL15, and it would be interesting to examine this gene in future studies. 
A recent case-control study reported association between haplotypes of five IL15 SNPs and asthma in a German population; no significant association was observed with any of the SNPs separately. ${ }^{37}$ In our study, different haplotypes showed association to different phenotypes in the two samples. Analysing the samples together a single three-SNP-haplotype showed evidence of under-transmission for positive RAST test. However, considering the number of tests performed and the lack of convergent results in the two samples, we conclude that IL15 does not play a major role in the aetiology of asthma and related atopic disorders in the Danish population.

To our knowledge, we are the first to report association between IL2 gene variants and IgE-mediated allergy (positive RAST test/skin prick test), asthma and AD (eczema). Regarding the association observed for the promoter SNP functional evidence support that the observed overtransmission of the $\mathrm{T}$ allele may convey increased disease susceptibility by a relative decrease in IL2 expression skewing the Th1/Th2 balance towards Th2. However, further studies are needed to shed light on this matter.

\section{Acknowledgements}

We thank the families for participating in the project. Brage Storstein Andresen is thanked for fruitful discussions regarding splicing.

The study was supported by grants from the Hørslev foundation, The Faculty of Health Sciences, University of Aarhus, The Aarhus University Research Foundation, ALK Abello the Aage Bang foundation, The Danish Lung Association, The Danish Asthma-Allergy Association, the Ville Heise, the Mimi and Victor Larsen, the Ellen Pedersen, the Marie Dorthea and Holger From Haderslev, and the Augustinus Foundations.

\section{References}

1 Cookson W: Genetics and genomics of asthma and allergic diseases. Immunol Rev 2002; 190: 195-206.

2 Mortz CG, Lauritsen JM, Bindslev-Jensen C, Andersen KE: Prevalence of atopic dermatitis, asthma, allergic rhinitis, and hand and contact dermatitis in adolescents. The Odense Adolescence Cohort Study on Atopic Diseases and Dermatitis. Br J Dermatol 2001; 144: 523-532.

3 Tips RL: A study of the inheritance of atopic hypersensitivity in man. Am J Hum Genet 1954; 6: 328-343.

4 Schwartz M: Heredity in bronchial asthma; a clinical and genetic study of 191 asthma probands and 50 probands with Baker's asthma. Acta Allergol Suppl (Copenh) 1952; 67: 1-288.

5 Palmer LJ, Burton PR, James AL, Musk AW, Cookson WO: Familial aggregation and heritability of asthma-associated quantitative traits in a population-based sample of nuclear families. Eur J Hum Genet 2000; 8: 853-860.

6 Hanson B, McGue M, Roitman-Johnson B, Segal NL, Bouchard Jr $\mathrm{TJ}$, Blumenthal $\mathrm{MN}$ : Atopic disease and immunoglobulin $\mathrm{E}$ in twins reared apart and together. Am J Hum Genet 1991; 48: 873-879.

7 Duffy DL, Martin NG, Battistutta D, Hopper JL, Mathews JD: Genetics of asthma and hay fever in Australian twins. Am Rev Respir Dis 1990; 142: 1351-1358.

8 Skadhauge LR, Christensen K, Kyvik KO, Sigsgaard T: Genetic and environmental influence on asthma: a population-based study of 11,688 Danish twin pairs. Eur Respir J 1999; 13: 8-14.
9 Larsen FS, Holm NV, Henningsen K: Atopic dermatitis. A geneticepidemiologic study in a population-based twin sample. $J \mathrm{Am}$ Acad Dermatol 1986; 15: 487-494.

10 Haagerup A, Bjerke T, Schoitz PO, Binderup HG, Dahl R, Kruse TA: Allergic rhinitis - a total genome-scan for susceptibility genes suggests a locus on chromosome 4q24-q27. Eur J Hum Genet 2001; 9: 945-952.

11 Haagerup A, Borglum AD, Binderup HG, Kruse TA: Fine-scale mapping of type I allergy candidate loci suggests central susceptibility genes on chromosomes $3 \mathrm{q}, 4 \mathrm{q}$ and Xp. Allergy 2004; 59: 88-94.

12 Wang R, Ciardelli TL, Russell JH: Partial signaling by cytokines: cytokine regulation of cell cycle and Fas-dependent, activation-induced death in CD4+ subsets. Cell Immunol 1997; 182: $152-160$.

13 Malek TR: The main function of IL-2 is to promote the development of $\mathrm{T}$ regulatory cells. I Leukoc Biol 2003; 74: 961-965.

$14 \mathrm{Ku}$ CC, Murakami M, Sakamoto A, Kappler J, Marrack P: Control of homeostasis of CD8+ memory T cells by opposing cytokines. Science 2000; 288: 675-678.

15 Grabstein KH, Eisenman J, Shanebeck K et al: Cloning of a T cell growth factor that interacts with the beta chain of the interleukin-2 receptor. Science 1994; 264: 965-968.

16 Yan K, Salome C, Woolcock AJ: Rapid method for measurement of bronchial responsiveness. Thorax 1983; 38: 760-765.

17 Vestbo J, Thomas W: Asthma and genes in a Danish population: outline of an on-going study. The ASTHMAGEN study group. Eur Respir Rev 2000; 10: 396-399.

18 Sobel E, Lange K: Descent graphs in pedigree analysis: applications to haplotyping, location scores, and marker-sharing statistics. Am J Hum Genet 1996; 58: 1323-1337.

19 Abecasis GR, Cookson WO: GOLD - graphical overview of linkage disequilibrium. Bioinformatics 2000; 16: 182-183.

20 Horvath S, Xu X, Lake SL, Silverman EK, Weiss ST, Laird NM: Family-based tests for associating haplotypes with general phenotype data: application to asthma genetics. Genet Epidemiol 2004; 26: 61-69.

21 Horvath S, Xu X, Laird NM: The family based association test method: strategies for studying general genotype-phenotype associations. Eur J Hum Genet 2001; 9: 301-306.

22 Spielman RS, Ewens WJ: The TDT and other family-based tests for linkage disequilibrium and association. Am J Hum Genet 1996; 59: 983-989.

23 Werner T: Computer-assisted analysis of transcription control regions. Matinspector and other programs. Methods Mol Biol 2000; 132: $337-349$.

24 Quandt K, Frech K, Karas H, Wingender E, Werner T: MatInd and MatInspector: new fast and versatile tools for detection of consensus matches in nucleotide sequence data. Nucleic Acids Res 1995; 23: 4878-4884.

25 Cartegni L, Wang J, Zhu Z, Zhang MQ, Krainer AR: ESEfinder: a web resource to identify exonic splicing enhancers. Nucleic Acids Res 2003; 31: 3568-3571.

26 Reese MG, Eeckman FH, Kulp D, Haussler D: Improved splice site detection in Genie. J Comput Biol 1997; 4: 311-323.

27 Luna L, Skammelsrud N, Johnsen O et al: Structural organization and mapping of the human TCF11 gene. Genomics 1995; 27: 237-244.

28 Husberg C, Murphy P, Martin E, Kolsto AB: Two domains of the human bZIP transcription factor TCF11 are necessary for transactivation. J Biol Chem 2001; 276: 17641-17652.

29 Shaulian E, Karin M: AP-1 as a regulator of cell life and death. Nat Cell Biol 2002; 4: E131-136.

30 Kitagawa-Sakakida S, Schwartz RH: Multifactor cis-dominant negative regulation of IL-2 gene expression in anergized T cells. J Immunol 1996; 157: 2328-2339.

31 Kang SM, Beverly B, Tran AC, Brorson K, Schwartz RH, Lenardo MJ: Transactivation by AP-1 is a molecular target of T cell clonal anergy. Science 1992; 257: 1134-1138. 
32 Jain J, Valge-Archer VE, Rao A: Analysis of the AP-1 sites in the IL-2 promoter. J Immunol 1992; 148: 1240-1250.

33 Hoffmann SC, Stanley EM, Darrin Cox E et al: Association of cytokine polymorphic inheritance and in vitro cytokine production in anti-CD3/CD28-stimulated peripheral blood lymphocytes. Transplantation 2001; 72: 1444-1450.

34 Matesanz F, Fedetz M, Leyva L, Delgado C, Fernandez O, Alcina A: Effects of the multiple sclerosis associated -330 promoter polymorphism in IL2 allelic expression. I Neuroimmunol 2004; 148: $212-217$.
35 Johnsen O, Murphy P, Prydz H, Kolsto AB: Interaction of the CNC-bZIP factor TCF11/LCR-F1/Nrf1 with MafG: binding-site selection and regulation of transcription. Nucleic Acids Res 1998; 26: $512-520$.

36 Nieters A, Linseisen J, Becker N: Association of polymorphisms in Th1, Th2 cytokine genes with hayfever and atopy in a subsample of EPIC-Heidelberg. Clin Exp Allergy 2004; 34: 346-353.

37 Kurz T, Strauch K, Dietrich H et al: Multilocus haplotype analyses reveal association between 5 novel IL-15 polymorphisms and asthma. J Allergy Clin Immunol 2004; 113: 896-901. 